\title{
Assessing the need and potential of assisted migration using species distribution models
}

Hällfors $\mathrm{MH}^{* \mathrm{a}}$, Aikio $\mathrm{S}^{\mathrm{a}}$, Fronzek $\mathrm{S},{ }^{\mathrm{b}}$ Hellmann $\mathrm{JJ}^{\mathrm{c}}$, Ryttäri $\mathrm{T}^{\mathrm{d}}$, Heikkinen $\mathrm{RK}^{\mathrm{d}}$

${ }^{a}$ Botany Unit, Finnish Museum of Natural History, P.O. Box 7, FI-00014 University of Helsinki, Finland

${ }^{\mathrm{b}}$ Climate Change Programme, Finnish Environment Institute, P.O. Box 140, FI-00251 Helsinki, Finland

${ }^{\mathrm{c}}$ Institute on the Environment, University of Minnesota, St. Paul, MN 55108 USA

${ }^{\mathrm{d}}$ Natural Environment Centre, Finnish Environment Institute, P.O. Box 140, FI-00251 Helsinki, Finland

* corresponding author: Maria Hällfors, Botany Unit, Finnish Museum of Natural History, P.O.

Box 7, FI-00014 University of Helsinki, Finland; maria.hallfors@helsinki.fi, tel. +35840 7213474

Type of article: Research paper

\section{Word count:}

Abstract 248 words

Text 7211 words

54 References

1 Table, 4 Figures, \& Supplementary material 


\begin{abstract}
Assisted migration (AM) has been suggested as a management strategy for aiding species in reaching newly suitable locations as climate changes. Species distribution models (SDMs) can provide important insights for decisions on whether to assist a species in its migration; however, their application includes uncertainties. In this study, we use consensus SDMs to model the future suitable areas for 13 vascular plant species with poor dispersal capacity. Based on the outputs of SDMs under different climate change scenarios and future times, we quantify the predicted changes in suitable area by calculating metrics that describe need and potential for migration. We find that, by the end of the $21^{\text {st }}$ century, one of the species would benefit from AM under mild climate change, seven under moderate change, and for 12 out of 13 species studied AM appears to be a relevant conservation method under strong climate change. We also test the effect of different modeling attributes on the metrics and find little variation between SDMs constructed using different combinations of modeling methods and variable sets. However, choice of climate variables had a larger influence on the level of the metrics than did the modeling method. We therefore suggest that choice of climate variables should receive ample attention when measuring climate change threat using SDMs and that experiments aiming to uncover critical environmental factors for individual species should be extensively conducted. This study illustrates that dispersal assistance may be needed for many species under a wide range of possible future climates.
\end{abstract}

Keywords: assisted colonization, conservation planning, managed relocation, model uncertainty, translocation 


\section{Introduction}

Climate change is projected to cause accelerating changes in species' distributions and abundances, resulting, at worse, to increased risk of extinction (Dawson et al. 2011, Urban 2015). Species may adjust to climatic changes by adapting in situ or by dispersing to areas where climate is becoming favorable (Dawson 2011, Moritz and Agudo 2013). However, the ability of species to adapt via evolutionary changes may be limited (Settele et al. 2014), and poor mobility and dispersal barriers may hamper their dispersal to new areas (Schloss et al. 2012, Corlett and Wescott 2013). Under such circumstances, human intervention in the form of conservation and adaptation actions may allow persistence of species. Assisted migration (AM; also referred to as managed relocation or assisted colonization; Richardson et al. 2009, Seddon 2010, Hewitt et al. 2011, Hällfors et al. 2014) has been suggested as one of several management strategies for aiding species in adjusting to rapid climate change (Chauvenet et al. 2012) and approaches for recognizing species that would benefit from AM have been presented (e.g., Hoegh-Guldberg et al. 2008, Richardson et al. 2009, Perez et al. 2012).

Deciding on AM for particular species involves various questions that range from ecological evaluations to assessments of invasion potential, legal constraints, and societal acceptability (Richardson et al. 2009, Schwartz 2012). Nonetheless, AM frameworks often begin with an assessment of the ecological threats stemming from climate change (e.g. Hoegh-Guldberg et al. 2008, Richardson et al. 2009, Rout et al. 2013). Climate change vulnerability assessments (Pacifici et al. 2015) provide useful general insights for recognizing candidate species but they cannot specify whether AM is an effective and necessary method to enable persistence of a certain species, as they only characterize climate change sensitivity. In comparison, developing predictions of spatial changes in suitable area using, e.g., species distribution models (SDMs) and climate scenario projections from General Circulation Models (GCMs) can generate information on climate change exposure and be used in guiding conservation efforts (Schwartz 2012, Guisan et al. 2013). In the context of AM, SDMs would typically be used to provide 'first-filter' assessments of climatically suitable areas for species translocation. Here we use distribution data on dispersal-limited European vascular plant species to model range change and quantify their need and potential for assisted species' dispersal. The theoretical basis for this approach is described in Hällfors et al. (manuscript), and this study provides the first empirical application of the approach.

The ultimate reason for using AM would be to avoid extinction of the focal species. Modelgenerated projected spatial changes in suitable area can be categorized as loss and gain of area of potential occupancy (Thomas et al. 2011). For AM to be relevant, a species needs to 1) have a need for migration, i.e., experience a considerable loss of suitable area, 2) have potential for migration, i.e., experience a considerable gain of new suitable area, and 3) have an inability to disperse, i.e., it cannot make use of the gained area (Hällfors et al. manuscript).

Here, we apply SDMs and use the results to quantify AM suitability for 13 vascular plant species, selected for poor dispersal ability, under various climate change scenarios and time periods. We first assess the migration need and migration potential for our study species by comparing the current range of the species and SDM projections of future suitable area. Next we combine these to arrive at an index that can be categorized based on thresholds to describe potential AM benefit (for details see Hällfors et al. manuscript). High values of the index indicate that the species has both the need of AM and high potential for AM to be effective.

We also address various sources of uncertainty in SDMs (Heikkinen et al. 2006, Synes \& Osborne 2011, Schwartz 2012) as they are likely to affect any quantitative metrics based on SDM outputs. 
We develop multiple SDMs for our study species, using different modeling methods and sets of climatic predictor variables. We also develop projections of suitable areas under different climate change scenarios and for different time periods under the $21^{\text {st }}$ century. This allows us to distinguish scenario-specific and temporal trajectories for the metrics as each species receives a value describing migration need and potential for each scenario and time period that the model is projected onto. We report the calculated metrics based on a consensus approach (Araujo and New 2007) of the SDMs, i.e., predictions supported by the majority of the SDMs. However, to gain insight into the degree of variation in the results that the choice of modeling method and climate variable set can bring about, we also test the effect of these choices on the metrics.

\section{Material and methods}

\subsection{Study species and distribution data}

Our study area includes land area in Eurasia occurring between 10.4 and 70.1 decimal-degrees East longitude and 34.1 and 72.1 decimal-degrees North latitude (Fig. 1). Within this area, we focus on 13 herbaceous plant species (nine herbs, two sedges and two grasses) that have poor dispersal ability. Dispersal ability was evaluated through information on seed weight and dispersal mode, as seed weight strongly affect the degree to which plant species can spread into new locations (Parolo and Rossi 2008; Table A1). The main part of all species' distribution fall within the study area (Figure A1). In general, they occur in western and central Europe and are scarce in northern Europe and the eastern portion of the study area. Additional selection criteria included the species being threatened in one or several countries in Europe and the availability of occurrence data through GBIF (Global Biodiversity Information Facility; GBIF 2013).

We compiled occurrence data from two complementary sources to augment the GBIF data. First, we included data from Finnish national databases (Kastikka [Finnish plant distribution database; Lampinen et al. 2011], and Hertta [Finnish Environment Institute, unpublished database]) since these data were not available through GBIF at the time of occurrence data gathering. Second, because the GBIF data showed certain apparent gaps, especially in the Eastern and Southern parts of the study area, we complemented the occurrence data with the range maps of Hultén and Fries (1986). This information was manually added by turning grid cells from unoccupied to occupied based on the range maps. The species and climate data were agglomerated using a regular lattice system over the study area with 10' x 10' grid cells, including 77404 cells in total. Each grid cell was assigned as "present" for a species if at least one occurrence point fell into that cell; otherwise, the species was assigned "absent."

\subsection{Climatic data}

In this study, we focused on identifying broadly-suitable climatic conditions to evaluate whether translocation would benefit the species in terms of projected changes in climatically suitable area. Therefore, we only use climatic variables to describe species distributions. This offers an efficient way to assess the degree to which climate change may affect a species, as climatic data and projections are readily available and climatic parameters have been shown to explain species occurrences well (Bucklin et al. 2015).

Data on current climatic conditions averaged for the period 1961-1990 were obtained from the CRU CL 2.0 global gridded dataset (New et al. 2002) that provides monthly mean temperature and precipitation in a spatial resolution of 10' $\mathrm{x} 10^{\prime}$ grid cells. Climate scenarios were constructed using an ensemble of 42 GCMs that took part in the 5th phase of the Climate Model Intercomparison 
Project (CMIP5; Taylor et al. 2011). Three simulations representing mild (GISS - GISS-E2$\mathrm{R} / \mathrm{RCP} 2.6$ ), moderate (MIROC5/RCP4.5), and strong (MIROCESM/RCP8.5) climatic change in Europe by 2100 were selected (Table A2). Climate scenarios were constructed by adding simulated changes in monthly mean temperature and, as relative changes, precipitation to the observed climatology. This was done for four overlapping 30-year periods for the 21st century: 2010-2039, 2030-2059, 2050-2079, and 2070-2099.

From the observed climate data and climate scenario data, we constructed eight climatic variables. They included four temperature related variables: annual mean temperature $\left({ }^{\circ} \mathrm{C}\right)$, mean temperature of the warmest month $\left({ }^{\circ} \mathrm{C}\right)$, mean temperature of the coldest month $\left({ }^{\circ} \mathrm{C}\right)$, annual growing degree days above $5^{\circ} \mathrm{C}$ (calculated by interpolating monthly mean temperature to daily values using a sine-curve interpolation); and four precipitation related variables: annual precipitation sum $(\mathrm{mm})$, mean winter precipitation $(\mathrm{mm}$; summed means of precipitation in December-February), mean summer precipitation ( $\mathrm{mm}$; summed mean of precipitation in JuneAugust), and annual water deficit ( $\mathrm{mm})$. The last variable was calculated as the annual sum of the monthly differences between potential evapotranspiration (PET) and precipitation for those months when PET exceeds precipitation. In turn, PET was calculated for each month based on mean monthly temperature (TMP) following Skov \& Svenning (2004):

$$
\mathrm{PET}=58.93^{*} \mathrm{TMP} / 12 \mid \text { if } \mathrm{TMP}>0 \text {, else } \mathrm{PET}=0 .
$$

These parameters were used to construct three different sets of climatic variables, with which SDMs were calibrated.

\subsection{Constructing variable sets}

The choice of predictor variables, including climatic variables, is one of the challenges in building SDMs (Synes and Osborne 2011, Barbet-Massin and Jetz 2014). This difficulty stems from limited understanding of what environmental factors govern the distributions of species. Methodological aspects that affect the delimitation of variable sets include collinearity problems (Dormann et al. 2013) and potential over-fitting of the models (Beumont et al. 2005). The way in which these challenges are tackled may affect the projections of spatial changes in species' area. Here, we considered selection based on: 1) avoiding over-fitting vs. avoiding exclusion of ecologically relevant variables (Braunisch et al. 2013), 2) statistical criteria (Austin and van Niel 2011, Synes and Osborne 2011), and 3) ecological relevance. On the basis of these three variable selection approaches we constructed three partially different variable sets for each study species.

\section{Set 1 - All eight climatic variables.}

Inclusion of too many variables into SDMs may cause over-fitting of the models (Beaumont et al. 2005). However, Braunisch et al. (2013) argue that selecting one or few variables from a set of correlated variables using various statistical rules may result in exclusion of potentially important variables. To avoid this, it may be better to include all the variables considered as potentially ecologically plausible into the models. This approach is considered useful especially for SDMs based on machine-learning algorithms such as MaxEnt (Merow et al. 2013) and generalized boosted models which are better equipped to deal with collinearity problems than many other modeling methods (Braunisch et al. 2013). Thus, we defined variable set 1 to consist of all eight variables, for all the 13 study species.

\section{Set 2 - The most important uncorrelated variables.}

Our second set of variables was constructed based on statistical selection rules. To avoid 
collinearity while selecting statistically important variables, we constructed the second set of climatic variables based on between-variable Pearson correlations (Fig. A1) and information on variable importance for all variables (Set 1) obtained from biomod2 (Thuiller et al. 2009; Table A3). The eight climate variables included were ranked according to their importance for each modeling method and each species. The first variable chosen for a given species was the one that gained the highest ranking value. Thereafter, following Barbet-Massin and Jetz (2014), we selected the second and third variable for each species so that the variable with the next highest ranking value was selected, but only if it showed a correlation value of $|r|<0.7$ with the already-included variables. This gave us a different set of three variables for each species which are not strongly inter-correlated and which represent, in statistical terms, the best predictors of the distribution patterns of the studied species (Table A3).

\section{Set 3 - Ecologically meaningful variables for plant species.}

We chose climatic variables that are ecologically relevant and therefore deterministic of vascular plant species ranges. Based on a literature search, we identified three main types of variables representing three important aspects of climate: variation in summer and winter temperatures and available moisture (Sykes et al. 1996; Bakkenes 2002). We focused on three commonly used variables to represent these: mean temperature of coldest month, growing degree days above $5^{\circ} \mathrm{C}$, and annual water deficit. Set 3 thus consisted of the same variables for all species.

\subsection{Modeling methods}

We used three modeling methods representing different approaches (Elith \& Graham 2006, Heikkinen et al. 2006). Two of them were presence-absence techniques: generalized linear model (GLMs with binomial distribution and logistic link) and generalized boosted model (GBM). GBM is a non-parametric model that uses boosting to approve the accuracy of prediction (Elith et al. 2008; Thuiller et al. 2009). The third technique was MaxEnt (Phillips et al. 2006), which is a machine-learning method that uses presence-only data and creates background points within the entire study area to describe it.

\subsection{SDM calibration, validation, and constructing consensus outputs}

In addition to exploring climatic projections of three different emission scenarios, we examined uncertainty in two other potential sources of variation: 1) selection of modeling method (i.e., SDM algorithm), and 2) selection of the climatic variables for the SDMs. Thus, we developed nine different SDMs (three variable sets [section 2.3. above] combined with three modeling methods [section 2.4. above]) for each of our study species. These nine SDMs were calibrated with observed climate and species occurrence data and then fitted into data representing three different climate scenarios (mild, moderate, and strong) averaged over four future time periods (section 2.2. above). The nine SDM projections for the three climate change scenarios and different time periods were examined both using consensus projections to evaluate AM benefit for the species (also called ensemble modeling; Araújo and New 2007, Schwartz 2012) and separately as individual SDMs to test the effect of modeling attributes on the metrics describing AM need and potential.

All nine SDMs for each 13 species were calibrated using Biomod2 (Thuiller et al., 2009) in R (R Core Team, 2014), and their performance was evaluated using a split-sample approach, with $80 \%$ of data used for calibration and $20 \%$ for validation. In the model calibration phase, the presence/absence data were weighted so that a prevalence of 0.5 was achieved for each study species (cf. McPherson et al. 2004). Model performance was evaluated using the area under the 
receiver operating characteristics (ROC) curve (AUC; Fielding and Bell 1997) and the true skill statistic (TSS; Allouche et al. 2006).

Next, all nine calibrated SDMs were projected on current conditions and on 12 future time period and climate change scenario combinations, resulting in 117 outputs per species. We converted the probabilities for climatic suitability for each projection into binary outputs of suitable and unsuitable areas. This conversion was done using the value at which the sum of sensitivity and specificity is maximized as a threshold (maximum sum of sensitivity versus specificity; Liu et al. 2005). To obtain consensus outputs, we combined the binary output of all nine models for the same time period and climate change scenario using a majority-vote approach, i.e., a cell was considered suitable if four or more of the nine outputs defined it as suitable.

\subsection{Identifying AM candidates}

We calculated migration need $\left(\mathrm{M}_{\mathrm{Need}, \mathrm{t}}\right)$ and migration potential $\left(\mathrm{M}_{\text {Potential, } \mathrm{t}}\right)$ for each species based on the number of presence cells in the occurrence data and on the predicted number of climatically suitable cells at different time steps $(t)$ in the future (Hällfors et al. manuscript). The size of the original area $\left(\mathrm{A}_{\text {Original }}\right)$ at the initial time point of assessment $(\mathrm{t}=0)$ consists of the presence cells in our data for which the nominal time period of $A_{\text {Original }}$ is 1961-1990 (the time period for which the SDMs were calibrated, when most of the species occurrence data were originally gathered, and the distribution maps of Hultén and Fries (1986) were drawn). Remnant area ( $\left.A_{\text {Remnant, } t}\right)$ consists of the cells of the original distribution that are climatically suitable up to the modelled time point in the future. New area $\left(\mathrm{A}_{\mathrm{New}, \mathrm{t}}\right)$ consists of cells that were not originally suitable, but are predicted to be suitable during the modelled future time period.

$A_{\text {Original }}, A_{\text {Remnant,t }}$, and $A_{N e w, t}$ were used for calculating the migration need and potential. $M_{\text {Need,t }}$ is defined as the proportion of lost $A_{\text {Original, }}\left(\right.$ Eq. 2), $M_{\text {Potential,t }}$ as the proportion of $A_{N e w, t}$ to all suitable cells (Eq. 3), and the $\mathrm{AM}$ index $\left(\mathrm{I}_{\mathrm{AM}, \mathrm{t}}\right)$ as the geometric mean of $\mathrm{M}_{\text {Need,t }}$ and $\mathrm{M}_{\text {Potential, }}$ (Eq. 4), as follows:

$M_{\text {Need }, t}=\frac{A_{\text {Original }}-A_{\text {Remnant }, t}}{A_{\text {Original }, t}}$

$$
M_{\text {Opportunity }, t}=\frac{A_{N e w, t}}{A_{N e w, t}+A_{\text {Remnant }, t}}
$$

The $\mathrm{AM}$ index and its components $\left(\mathrm{M}_{\mathrm{Need}, \mathrm{t}}\right.$ and $\left.\mathrm{M}_{\text {Potential,t }}\right)$ range from 0 to 1 and will vary in different time periods as the predicted size of the area suitable for occupancy changes over time. A high AM index value indicates that the species has both the need (a considerable amount of suitable area is lost) and the potential (a considerable amount of suitable area is gained compared to what remains) for AM (Hällfors et al. manuscript).

The consensus outputs were used for identifying candidates for AM through converting the $\mathrm{I}_{\mathrm{AM}}$ into categories describing benefit of AM for the species. We adapted Thomas et al.'s (2011) evaluation 
framework for incorporating red list-based decadal losses and increases in distribution areas of species under climate change to translate our results in decadal changes in distribution area to categories of AM benefit (see Hällfors et al. manuscript for details). The $\mathrm{I}_{\mathrm{AM}, \mathrm{t}}$ values that correspond to these percentages depend on the modelled time span, which in the current study is up to eleven decades ( $[\mathrm{t}=11]$ from $1970(1961-1990)$ to 2080 (2070-99), and the corresponding threshold is: $\mathrm{I}_{\mathrm{AM}, 11}=\left[1-\left(1-\text { percentage/100) }{ }^{\mathrm{t}}\right]^{1 / 2}\right.$; see Hällfors et al. manuscript, for details $)$. We interpret the resulting $\mathrm{I}_{\mathrm{AM}}$ threshold values so that, by $2070-99$, a species with $0.32<\mathrm{I}_{\mathrm{AM}, 11}<0.60$ is a possible candidate for $\mathrm{AM} ; 0.60<\mathrm{I}_{\mathrm{AM}, 11}<0.76$ is a probable candidate for $\mathrm{AM}$, while a species with even higher $\mathrm{I}_{\mathrm{AM}, 11}$ would be a strong candidate for AM.

\subsection{Effects of modeling attributes}

To evaluate the degree to which a random choice of individual SDM (with a certain combination of modeling method and climate variable set) could affect the value of the AM metrics, we tested the effect of modeling features, including scenario, time period, and original size of distribution area, on $\mathrm{M}_{\text {Potential, },}, \mathrm{M}_{\text {Need,t }}$ and $\mathrm{I}_{\mathrm{AM}, \mathrm{t}}$. We did an arcsine transformation of the response variables $\left(\mathrm{M}_{\text {Need,t, }}\right.$ $\mathrm{M}_{\text {Potential,t }}$ and $\mathrm{I}_{\mathrm{AM}, \mathrm{t}}$ ) and used a linear mixed model with a Gaussian distribution (lme function in the nlme package in R). As explanatory variables, we used $A_{\text {original }}$, Modeling method, Variable set, and Scenario. We used Time period and Species as random effects, with Species nested within Time period. We performed model selection to estimate importance of the factorial fixed effects and started from a full model that included all explanatory variables and two-way interactions. We used the dropl function and compared Akaike Information Criterion values (AIC), selecting the model with the lowest AIC value in a step-wise manner. To evaluate significance of variables in the final model, we used an ANOVA comparison of the final model with alternative models from which one variable or (and) interaction was omitted at a time. For this, we re-fitted the models using the lmer function in the lme 4 package to obtain difference in deviance, degrees of freedom, and probabilities (Table 1).

\section{Results}

\subsection{SDMs and general results}

All SDMs developed for the 13 study species showed excellent model fit as they had AUC values higher than 0.94 and TSS higher than 0.77 (Table A4). Areas projected to be climatically suitable for the species tended to shift towards the north and east with increasing time and severity of climate change. As expected, these shifts were more pronounced under moderate and strong climate change and later time periods than for mild climate change or projections into the near future (projection maps of Carex pulicaris Fig. 1; all species Fig. A2).

\subsection{Migration need and potential, and AM benefit category}

The stronger the projected climate change, the higher was the AM index based on migration need and potential (Carex pulicaris presented as an example in Fig. 2; all species in Fig. A3; data used to calculate metrics and metric values in Table A5), and the higher was the AM benefit category that a species received (species per category in 2070-2099 Fig. 3; number of species per category, time period and scenario in Table A6). For the mild climate change scenario, only one species (Sisymbrium supinum; Fig. 3) was evaluated to be a possible candidate for AM by late $21^{\text {st }}$ century, while the rest were not categorized as candidates for AM. For the moderate scenario, six species were possible candidates, while Primula farinosa was categorized as a strong candidate for AM. Under the strongest climate change scenario, all our study species except Bromus benekenii were 
identified as candidates for AM (possible, probable, or strong; Fig. 3). Converted into percentages, a mild climate change scenario implies that $7.7 \%$ of the studied species would be AM candidates by the end of the $21^{\text {st }}$ century, whereas $53.8 \%$ and $92.3 \%$ of them would be AM candidates by the same time under a moderate and strong climate change scenario, respectively.

\subsection{Effect of modeling attributes on AM metrics}

Species with smaller $A_{\text {Original }}$ tended to have a higher $\mathrm{I}_{\mathrm{AM}, \mathrm{t}}$ and $\mathrm{M}_{\text {Need,t }}($ Fig. 4 (a-f); Table A7). However, A Ariginal was not important in explaining the variation in $\mathrm{I}_{\mathrm{AM}, \mathrm{t}}$ on its own. Instead, $\mathrm{I}_{\mathrm{AM}, \mathrm{t}}$ and $\mathrm{M}_{\text {Need,t }}$ decreased with increasing $\mathrm{A}_{\text {Original, }}$ at a rate that depends on the interaction with scenario and variable set (Table 1). $M_{\text {Potential, } t}$ decreased with $A_{\text {Original, } t}$ both by direct effect $(t=-4.83, p<0.01)$ and interactively with scenario, variable set, and modeling method (Table 1). However, the

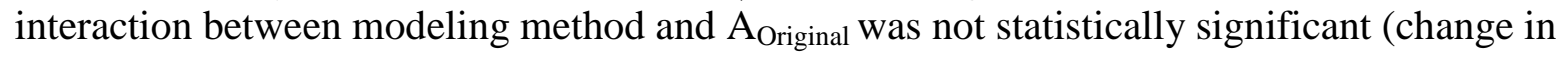
deviance by $4.6 ; \mathrm{p}=0.098$; Table 1 ).

The emissions scenario affected the size of the metric, with higher values under stronger climate change, especially for $\mathrm{M}_{\mathrm{Need}, \mathrm{t}}$ and $\mathrm{I}_{\mathrm{AM}, \mathrm{t}}$ (Table A7). The variable set had a clear grouping effect on the metrics, whereas the modeling method used did not (Fig. 4; Table A7). For $M_{\text {Potential,t }}$, variable set 3 (ecologically relevant variables) produced higher values under the moderate and strong scenarios (Fig. 4; Table A7). For $\mathrm{M}_{\mathrm{Need,t}}$ and $\mathrm{I}_{\mathrm{AM}, \mathrm{t}}$, variable set 3 tended to give rise to lower values while set 1 (all climate variables) had a larger interaction with $A_{\text {Original, }}$ producing proportionally higher values for smaller A $_{\text {Original }}$ (Fig. 4; Table A7).

\section{Discussion}

The AM index values, and the corresponding AM benefit categories, indicated a large difference in the proportion of AM candidates between climate change scenarios. AM was deemed a more potential conservation approach under stronger climate change and later into the future. The difference in the proportion of species being classified as AM candidates by the end of the century was striking, as 7\% (1 out of 13) of species were identified as AM candidates under a mild climate change scenario, while the corresponding percentage under a strong climate change scenario was over 90 (12 out of 13). These suggests a possible benefit of AM for our focal species, and illustrates the differences in conservation effort that may be needed under various scenarios of climate change. The same approach can readily be applied to other species with appropriate and available distribution and climate data; however, we recognize that during a more in-depth evaluation of actual decisions on AM application also depends other factors, such as habitat suitability, societal acceptability, and invasion potential (Richardson et al. 2009).

Our results are consistent with previous studies showing that extinction vulnerability, measured with SDMs, increases as range size decreases (Schwartz et al. 2006; Pearson et al. 2014). Species with smaller ranges in our study tended to have a higher AM index, $\mathbf{M}_{\mathrm{Need}, \mathrm{t}}$ and, especially, $M_{\text {Potential,t }}$ (occupied cell number ranged from 473 - 21 519; Table A5). The only species that was identified as a candidate for AM under a mild climate change was, in fact, the species with the smallest $\mathrm{A}_{\text {Original }}(S$. supinum). If a narrow niche is reflected by a small distribution area, this indicates that potentially vulnerable species are recognized in SDM-based threat evaluations (although see Schwartz et al. 2006 on prediction uncertainties connected to smaller distribution size). The reverse effect can also be seen in the negative correlation of distribution area size (Ariginal) and size of $\mathrm{M}_{\text {Potential, } t}$ : species with larger distribution areas tend to have a larger remnant area, which may be caused by a wider niche and broader tolerance increasing the probability of 
suitable conditions remaining within the current distribution area. Therefore, even a large $\mathrm{A}_{\mathrm{New}, \mathrm{t}}$ does not increase $M_{\text {Potential, }}$ substantially as $A_{\text {Remnant, } t}$ remains high, and further prohibits an increase in the AM index for species with large original occurrence areas.

Our analyses indicate that the choice of climate variable sets resulted in larger differences in the metrics than the choice of modeling method. Variable set 3, which consists of ecologically meaningful predictors, for example, gave rise to higher $\mathbf{M}_{\text {Potential,t }}$ and lower $\mathbf{M}_{\mathrm{Need}, \mathrm{t}}$ than the other variable sets, regardless of the modeling method. This suggests that our set of 'ecologically relevant climate variables' results in projections of less original area being lost due to climate change. In turn, this leads to lower $\mathrm{M}_{\mathrm{Need,t}}$ and a higher gain of area making $\mathrm{A}_{\mathrm{New}, \mathrm{t}}$ play a larger role in the total future suitable area, thereby increasing $M_{\text {Potential,t. }}$ Thus, in extinction vulnerability analyses, using this particular climate variable set in SDMs could cause lower estimates of extinction, similarly to affecting the AM index by lowering it. Variable set 2 (variables selected on a statistical basis) had the opposite effect as it gave rise to higher $\mathbf{M}_{\text {Need,t }}$ and lower $\mathbf{M}_{\text {Potential,t }}$, and ultimately a higher AM index. The predictions of climatically suitable areas based on variable set 1 (all 8 climate variables) fall in between these extremes. This identification of the intermediate can be viewed as support to the findings and recommendations of Braunisch et al. (2013), who recommend using all possibly relevant variables when the ecologically most critical ones are unknown.

The results from the modeling attribute analysis are encouraging since they suggests extensively detailed choices concerning modeling features may be given less attention when the objective of a study is to assess vulnerability as opposed to identifying exact locations of suitable conditions. However, we acknowledge that whether this holds for SDMs more generally requires a wider assessment where diverse geographic distributions, species types, modeling methods, and variables combinations are represented.

Our results simultaneously highlight the importance of obtaining a more mechanistic understanding of the physiological requirements of species, to enable more informed choices of climatic variables, since this choice had a relatively large influence on the results. Although climate variable set 3 was chosen to represent factors regarded as generally influential in plant species distributions (e.g., Sykes et al. 1996; Bakkenes 2002) it is not necessarily representative for the species included in this study nor for other specific species. Therefore, we cannot say whether the results gained using set 3 are more reliable than those gained using the other sets. Hence, using one or the other set may be equally prone to error. Although a daunting task if conducted for even a small part of all species known, field trials and common-garden experiments (Kawecki and Ebert 2004) are imperative for informing models, assessments, and planning (Morin and Thuiller 2009). Improved modeling that considers differences within species, including local adaptation, is also important to enable accurate predictions and planning for AM (Banta et al. 2012, Bocedi et al. 2013)

Other methodological and conceptual uncertainties involved with species distribution models can also influence the outcome of vulnerability assessments. For example, climate was the only environmental condition included in the SDMs of this study. The distribution of species, rare species in particular, may also be governed by other factors, such as biotic interactions, dispersal ability, soil type, and habitat availability. For example, B. benekenii was the only one of our study species that was not considered an AM candidate even under strong climate change. Our results thus indicate that the climatic conditions that we modeled based on its current range will persist and even become more common within Europe. However, floristic records from central Europe suggest that this species is confined to nutrient- and herb-rich deciduous forests, which illuminates the importance of considering non-climatic requirements along-side with climate when planning for AM. Adding further restrictions to species' environmental tolerances could result in more 
pessimistic estimates of potential future distribution, as the suitable conditions are further narrowed. Including additional information of species' environmental requirements may therefore provide more detailed and reliable estimates of potential distributions (e.g. Heikkinen et al. 2009), although it may come at the expense of increased need for data and model complexity. Therefore, the results presented here may be in the more conservative end of threat estimates. On the other hand, including information on dispersal or adaptive abilities could, for some species, have the reverse effect, resulting in a lower AM index. Developing readily available data and models for including such assumptions would greatly enhance our ability to predict and prepare for the future.

Until distribution modeling is improved through greater consideration of species' range dynamics, SDM-based assessments concentrating on climatic conditions have the potential to help characterize the consequences of climate change (Guisan et al. 2013) and, as we have shown here, to identify and distinguish species according to their need and potential of AM. Although more information is needed, approaches such as the one used here can provide a first approximation of the conservation needs of species. Specifically, our method identifies when a predicted change in range may necessitate AM. Managers can then incorporate this information in their overall evaluation where additional factors such as the risks associated with both action and inaction are included (Schwartz et al. 2009). If our focal species would be representative of other places and taxa, more than $90 \%$ of poorly dispersing vascular plant species may need AM under strong climate change, and this points to large challenges in biodiversity management as anthropogenic climate change proceeds.

\section{Acknowledgements}

MHH was supported by the University of Helsinki Research Fund and LUOVA - Doctoral Programme in Wildlife Biology Research. SA was supported by the Academy of Finland (decision 258144) and the Kone Foundation. SF acknowledges support from the Academy of Finland (decision 277276). We are grateful to M. Hyvärinen for advice on interpretation of linear mixed models. We acknowledge the World Climate Research Programme's Working Group on Coupled Modeling, which is responsible for CMIP, and we thank the climate modeling groups (listed in Table A2) for producing and making their model output available. For CMIP the U.S. Department of Energy's Program for Climate Model Diagnosis and Intercomparison provided coordinating support and led development of software infrastructure in partnership with the Global Organization for Earth System Science Portals.

\section{Glossary}

$\mathrm{A}_{\text {Original }}=$ Species distribution area size at the beginning of the assessment $(\mathrm{t}=0)$, based on observed or modelled distribution depending on the species and available occurrence data. The size of the distribution area may be measured in various units, such as the number of grid cells or $\mathrm{km}^{2}$. $A_{\text {Remnant }, t}=$ The part of $A_{\text {Original }}$ that remains suitable at a certain point of time $t$ in the future (measured in number of grid cells, $\mathrm{km}^{2}$, or similar).

$\mathrm{A}_{\mathrm{New}, \mathrm{t}}=$ The area (number of grid cells, $\mathrm{km}^{2}$, or similar) that was previously unsuitable but has become suitable at the time $t$ due to climate change.

$\mathrm{M}_{\text {Potential, } \mathrm{t}}=$ Migration potential, the prospect of migration when new area becomes suitable with change in climate, calculated as the proportion of new suitable area $\left(\mathrm{A}_{\mathrm{New}, \mathrm{t}}\right)$ from the total suitable area $\left(A_{\text {Remnant, } t}+A_{N e w, t}\right)$ at a certain point in time. A high value of $M_{\text {Potential, } t}$ indicates that climate change offers the species much potential for range expansion compared to what it has left. $\mathrm{M}_{\text {Need,t }}=$ Migration need, the relative need to compensate for the loss of range by climate change, calculated as the proportion of a species' original distribution area ( $\mathrm{A}_{\text {Original }}$ ) that will be lost due to climate change $\left(\mathrm{A}_{\text {Original }}-\mathrm{A}_{\mathrm{Remnan}, \mathrm{t}}\right)$. A high value of $\mathrm{M}_{\mathrm{Need}, \mathrm{t}}$ indicates that climate change makes 
much of the original area unsuitable wherefore the species has a high need for range expansion to maintain a distribution area of the same size.

$\mathrm{I}_{\mathrm{AM}, \mathrm{t}}=$ The assisted migration (AM) index calculated as the geometric mean of $\mathrm{M}_{\mathrm{Need}, \mathrm{t}}$ and $\mathrm{M}_{\text {Potentia,t } \mathrm{t}}$, indicating, on a scale between $0-1$, how applicable assisted migration might be as a conservation method for the species.

\section{References}

Allouche, O., Tsoar, A., Kadmon, R. 2006. Assessing the accuracy of species distribution models: prevalence, kappa and the true skill statistic (TSS). J. Appl. Ecol. 43, 1223-1232.

Araújo, M.B., New, M. 2007. Ensemble forecasting of species distributions. Trends Ecol. Evol. 22, $42-7$.

Austin, M.P., Van Niel, K.P. 2011. Improving species distribution models for climate change studies: variable selection and scale. J. Biogeogr. 38, 1-8.

Bakkenes, M., Alkemade, J.R.M., Ihle, F., Leemans, R., Latour, J.B. 2002. Assessing effects of forecasted climate change on the diversity and distribution of European higher plants for 2050. Global Change Biol. 8, 390-407.

Banta, J., et al. 2012. Climate envelope modeling reveals intraspecific relationships among flowering phenology, niche breadth and potential range size in Arabidopsis thaliana. Ecol. Lett. 15, 769-777.

Barbet-Massin, M., Jetz, W. 2014. A 40-year, continent-wide, multispecies assessment of relevant climate predictors for species distribution modeling. Divers. Distrib. 20, 1285-1295.

Beaumont, L.J., Hughes, L., Poulsen, M. 2005. Predicting species distributions: use of climatic parameters in BIOCLIM and its impact on predictions of species' current and future distributions. Ecol. Modell. 186, 251-270.

Bocedi, G., K. E. Atkins, J. Liao, R. Henry, J. M. J. Travis, J. J. Hellmann. 2013. Effects of local adaptation and inter-specific competition on species' responses to climate change. Annals of the New York Academy of Sciences 1297, 83-97.

Braunisch, V., Coppes, J., Arlettaz, R., Suchant, R., Schmid, H., Bollmann, K. 2013. Selecting from correlated climate variables: a major source of uncertainty for predicting species distributions under climate change. Ecography. 36, 971-983.

Bucklin, D.N., Basille, M., Benscoter, A.M., et al. 2015. Comparing species distribution model constructed with different subsets of environmental predictors. Divers. Distrib. 21, 23-35

Chauvenet, A.L.M., Ewen, J.G., Armstrong, D., Pettorelli, N. 2013. Saving the hihi under climate change: a case for assisted colonization. J. Appl. Ecol. 50, 1330-1340.

Corlett, R.T., Westcott, D.A. 2013. Will plant movements keep up with climate change? Trends 
Ecol. Evol. 28, 482-8.

Dawson, T. P., Jackson, S. T., House, J. I., Prentice, I. C., Mace, G. M. 2011. Beyond predictions: biodiversity conservation in a changing climate. Science. $332,53-8$.

Dormann, C.F., Elith, J., Bacher, S. et al. 2013. Collinearity: a review of methods to deal with it and a simulation study evaluating their performance. Ecography. 36, 27-46.

Elith, J., Graham, C.H. 2009. Do they? How do they? WHY do they differ? On finding reasons for differing performances of species distribution models. Ecography. 32, 66-77.

Elith, J., Leathwick, J.R., Hastie, T. 2008. A working guide to boosted regression trees. J. Anim. Ecol. 77, 802-813.

Fielding, A., Bell, J. 1997. A review of methods for the assessment of prediction errors in conservation presence/absence models. Environ. Conserv. 24, 38-49.

GBIF 2013. Global Biodiversity Information Facility Data Portal. www.gbif.org

Guisan, A., Tingley, R., Baumgartner, J.B., et al. 2013. Predicting species distributions for conservation decisions. Ecol. Lett. 16, 1424-1435.

Hällfors, M.H., Vaara, E.M., Hyvärinen, M., Oksanen, M., Schulman, L.E., Siipi, H., Lehvävirta, S. 2014. Coming to terms with the concept of moving species threatened by climate change $-\mathrm{a}$ systematic review of the terminology and definitions. PLOS ONE. 9(7), e102979.

Hällfors, M.H., Aikio, S., Schulman, L.E. manuscript. Quantifying the need and potential of assisted migration.

Heikkinen, R.K., Luoto, M., Araújo, M.B., Virkkala, R., Thuiller, W., Sykes, M.T. 2006. Methods and uncertainties in bioclimatic envelope modeling under climate change. Prog. Phys. Geogr. 30, $751-777$.

Heikkinen, R.K., Luoto, M., Leikola, N., et al. 2009. Assessing the vulnerability of European butterflies to climate change using multiple criteria. Biodivers. Conserv. 19, 695-723.

Hewitt, N., Klenk, N., Smith, A.L., et al. 2011. Taking stock of the assisted migration debate. Biol. Conserv. 144, 2560-2572.

Hoegh-Guldberg, O., Hughes, L., Mcintyre, S., et al. 2008. Assisted colonization and rapid climate change. Science. 321, 345-346.

Hultén, E., Fries, M. 1986. Atlas of North European vascular plants: north of the Tropic of Cancer, vol. 1-3. Königstein, Koeltz.

Kawecki, T.J., Ebert, D. 2004. Conceptual issues in local adaptation. Ecol. Lett. 7, 1225-1241.

Lampinen, R., Lahti, T., Heikkinen, M. 2012. Kasviatlas 2011. -- Helsingin Yliopisto,

Luonnontieteellinen keskusmuseo, Helsinki. Distribution maps available at:

http://www.luomus.fi/kasviatlas. 
Liu, C., et al. 2005. Selecting thresholds of occurrence in the prediction of species distributions. Ecography. 28, 385-393.

McPherson, J.M., Jetz, W., Rogers, D.J., 2004. The effects of species' range sizes on the accuracy of distribution models: ecological phenomenon or statistical artefact?. Journal of Applied Ecology. 41, 811-823.

Merow, C., Smith, M.J., Silander, J.A. 2013. A practical guide to MaxEnt for modeling species'distributions: what it does, and why inputs and settings matter. Ecography. 36, 1058-1069.

Morin, X., Thuiller, W. 2009. Comparing niche- and process-based models to reduce prediction uncertainty in species range shifts under climate change. Ecology. 90, 1301-1313.

Moritz, C., Agudo, R. 2013. The future of species under climate change: resilience or decline? Science. 341, 504-508.

New, M., Lister, D., Hulme, M., Makin, I. 2002. A high-resolution data set of surface climate over global land areas. Climate Research. 21, 1-25.

Pacifici, A.M., et al. 2015. Assessing species vulnerability to climate change. 5, 215-225.

Parolo, G., Rossi, G. 2008. Upward migration of vascular plants following a climate warming trend in the Alps. Basic Appl. Ecol. 9, 100-107.

Pearson, R.G., Stanton, J.C., Shoemaker, K.T., et al. 2014. Life history and spatial traits predict extinction risk due to climate change. Nature Climate Change. 4, 217-221.

Pérez, I., Anadón, J.D., Díaz, M., Nicola, G.G., Tella, J.L., Giménez, A. 2012. What is wrong with current translocations? A review and a decision-making proposal. Front. Ecol. Environ. 10, 494501.

Phillips, S., Anderson, R., Schapire, R. 2006. Maximum entropy modeling of species geographic distributions. Ecological Modeling. 190, 231-259.

R Core Team (2014) R: A language and environment for statistical computing. R Foundation for Statistical Computing, Vienna, Austria. <http://www.R-project.org/>.

Richardson, D.M., Hellmann, J.J., McLachlan, J.S., et al. 2009. Multidimensional evaluation of managed relocation. Proc. Natl. Acad. Sci. U.S.A. 106, 9721-4.

Rout, T.M., McDonald-Madden, E., Martin, T.G., Mitchell, N.J., Possingham, H.P., Armstrong, D.P. 2013. How to decide whether to move species threatened by climate change. PLOS ONE 8, e75814.

Schloss, C.A., Nuñez, T.A., Lawler, J.J. 2012. Dispersal will limit ability of mammals to track climate change in the Western Hemisphere. Proc. Natl. Acad. Sci. U.S.A. 109, 8606-11.

Schwartz, M.W. 2012. Using niche models with climate projections to inform conservation management decisions. Biol. Conserv. 155, 149-156. 
Schwartz, M.W., Iverson, I.R., Prasad, A.M., Matthews, S.N., O'Connor, R.J. 2006. Predicting extinctions as a result of climate change. Ecology. 87, 1611-1615.

Schwartz, M., Hellmann, J., McLachlan, J. 2009. The precautionary principle in managed relocation is misguided advice. Trends in Ecology and Evolution. 24, 474.

Seddon, P.J. 2010. From reintroduction to assisted colonization: moving along the conservation translocation spectrum. Restoration Ecology. 18, 796-802.

Settele, J.R. et al., 2014. Terrestrial and inland water systems. In: Climate Change 2014: Impacts, Adaptation, and Vulnerability. Part A: Global and Sectoral Aspects. Contribution of Working Group II to the Fifth Assessment Report of the Intergovernmental Panel on Climate Change [Field, C.B. et al., (eds.)]. Cambridge University Press, Cambridge, United Kingdom and New York, NY, USA, pp. 271-359.

Skov, F., Svenning, J.-C. 2004. Potential impact of climatic change on the distribution of forest herbs in Europe. Ecography. 27, 366-380.

Sykes, M.T., Prentice, I.C., Cramer, W. 1996. A bioclimatic model for the potential distributions tree species under present and future climates European. J. Biogeogr. 23, 203-233.

Synes, N.W., Osborne, P.E. 2011. Choice of predictor variables as a source of uncertainty in continental-scale species distribution modeling under climate change. Global Ecol. Biogeogr. 20, 904-914.

Taylor, K.E., Stouffer, R.J., Meehl, G.A. 2011. An overview of CMIP5 and the experiment design. Bulletin of the American Meteorological Society: 111007060139000

Thomas, C.D., Hill, J.K., Anderson, B.J., et al. 2011. A framework for assessing threats and benefits to species responding to climate change. Methods Ecol. Evol. 2, 125-142.

Thuiller, W., Lafourcade, B., Engler, R., Araujo, M.B. 2009. BIOMOD - A platform for ensemble forecasting of species distributions. Ecography. 32, 369-373.

Urban, M.C. 2015. Accelerating extinction risk from climate change. Science. 348(6234), 571-573. 
Table 1. Change in deviance (degree of model fit) when a single variable was omitted from the final linear mixed model. ModMet $=$ Modeling method; Set $=$ Variable set. Estimated values, standard deviations, $t$-values and $\mathrm{p}$-values for the linear mixed models used for testing the effect of modeling features on $\mathrm{I}_{\mathrm{AM}, \mathrm{t}}, \mathrm{M}_{\mathrm{Need}, \mathrm{t}}$, and $\mathrm{M}_{\text {Potential, }}$ in Table A7.

\begin{tabular}{|c|c|c|c|c|c|c|c|c|c|}
\hline \multirow[b]{2}{*}{ Variable } & \multicolumn{3}{|c|}{ Model for $I_{A M, t}$} & \multicolumn{3}{|c|}{ Model for $\mathbf{M}_{\text {Potential, } t}$} & \multicolumn{3}{|c|}{ Model for $\mathbf{M}_{\text {Need,t }}$} \\
\hline & $\begin{array}{l}\text { Change } \\
\text { in } \\
\text { devianc } \\
\text { e }\end{array}$ & df & $\begin{array}{c}\mathrm{p}- \\
\text { value }\end{array}$ & $\begin{array}{l}\text { Change } \\
\text { in } \\
\text { devianc } \\
\text { e }\end{array}$ & df & $\mathrm{p}$-value & $\begin{array}{l}\text { Change } \\
\text { in } \\
\text { devianc } \\
\text { e }\end{array}$ & df & $\begin{array}{c}\mathrm{p}- \\
\text { value }\end{array}$ \\
\hline ModMet & 16.38 & 2 & $<0.01$ & - & - & - & 13.17 & 2 & $<0.01$ \\
\hline ModMet: $\mathrm{A}_{\text {Original }}$ & - & - & - & 4.64 & 2 & $\begin{array}{r}0.0981 \\
2\end{array}$ & - & - & - \\
\hline ModMet:Set & - & - & - & 14.70 & 4 & $<0.01$ & - & - & - \\
\hline $\begin{array}{l}\text { ModMet }(+ \text { ModMet:Set + } \\
\left.\text { ModMet:A } A_{\text {Original }}\right)\end{array}$ & - & - & - & 20.00 & 8 & $<0.05$ & - & - & - \\
\hline $\begin{array}{l}\text { Set (+Set:Scenario + } \\
\text { Set:ModMet) }\end{array}$ & - & - & - & 143.76 & 10 & $<0.01$ & - & - & - \\
\hline $\begin{array}{l}\text { Set }(+ \text { Set:Scenario \& } \\
\left.\text { Set:A } A_{\text {Original }}\right)\end{array}$ & 95.53 & 8 & $<0.01$ & - & - & - & 152.43 & 8 & $<0.01$ \\
\hline $\begin{array}{l}\text { Scenario (+ Scenario: } \mathrm{A}_{\text {Original }}+ \\
\text { Scenario:Set) }\end{array}$ & - & - & - & 725.03 & 8 & $<0.01$ & - & - & - \\
\hline Scenario (+Scenario:Set) & - & - & - & - & - & - & 446.10 & 6 & $<0.01$ \\
\hline Scenario (+Scenario: $\left.A_{\text {Original }}\right)$ & 13.96 & 2 & $<0.01$ & - & - & - & - & - & - \\
\hline $\begin{array}{l}\mathrm{A}_{\text {Original }}\left(+\mathrm{A}_{\text {Original }}: \text { Scenario }+\right. \\
\left.\mathrm{A}_{\text {Original }}: \text { ModMet }\right)\end{array}$ & - & - & - & 116.42 & 5 & $<0.01$ & - & - & - \\
\hline$A_{\text {Original }}\left(+A_{\text {Original }}:\right.$ Set $)$ & 67.92 & 2 & $<0.01$ & - & - & - & - & - & - \\
\hline $\begin{array}{l}\mathrm{A}_{\text {Original }}\left(+\mathrm{A}_{\text {Original }}: \text { Scenario }+\right. \\
\left.\mathrm{A}_{\text {Original }}: \text { Set }\right)\end{array}$ & - & - & - & - & - & - & 100.74 & 5 & $<0.01$ \\
\hline
\end{tabular}



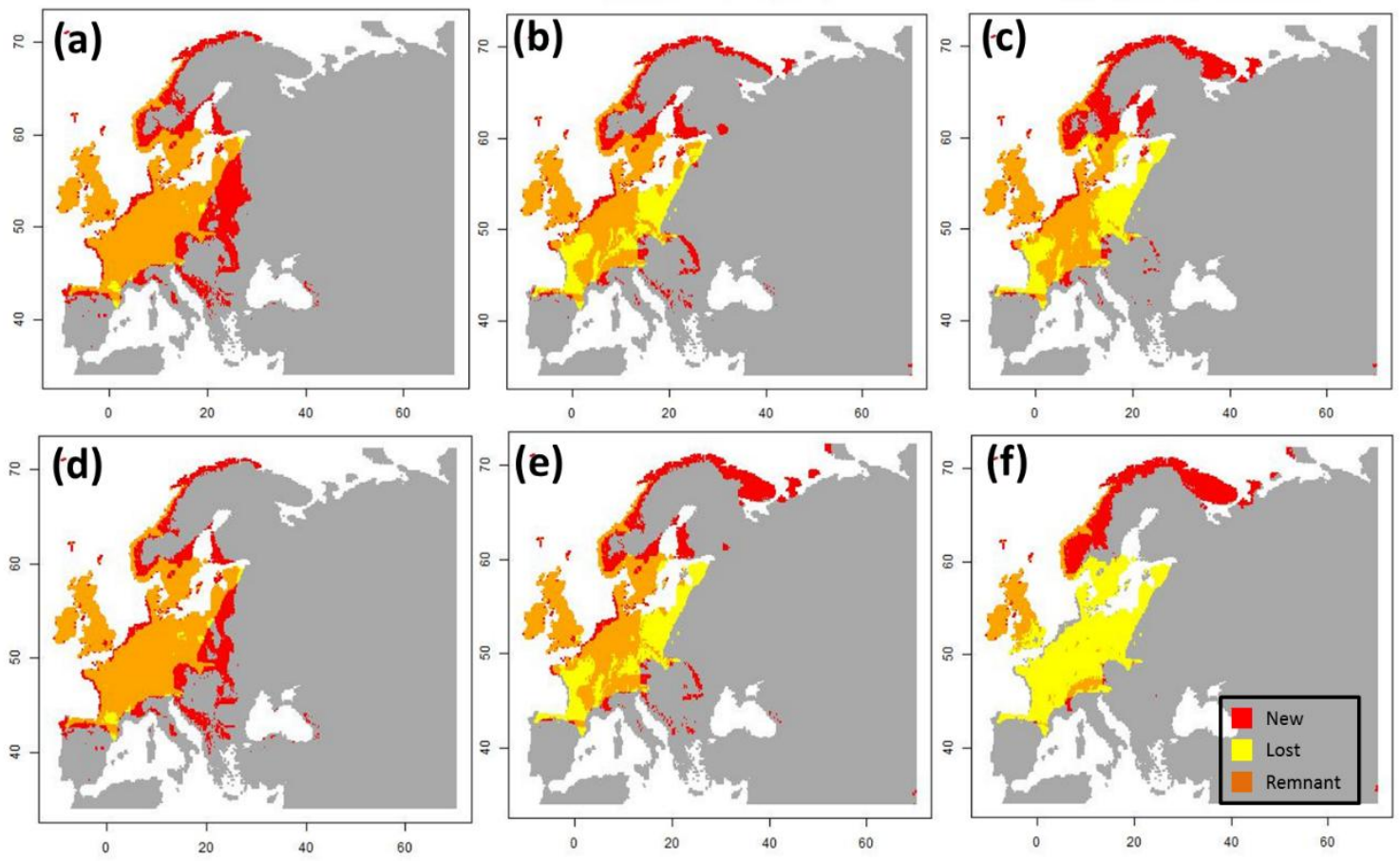

Fig. 1. Consensus output maps based on multiple species distribution models for Carex pulicaris under a) mild, b) moderate, and c) strong climate change scenario in 2030-59, and d) mild, e) moderate, and f) strong climate change scenario in 2070-99. Red $=$ New areas, Yellow $=$ Lost (no longer climatically suitable) areas, orange $=$ Remnant areas; yellow and orange areas together make up original distribution area. For corresponding maps for all species see Fig A1. 

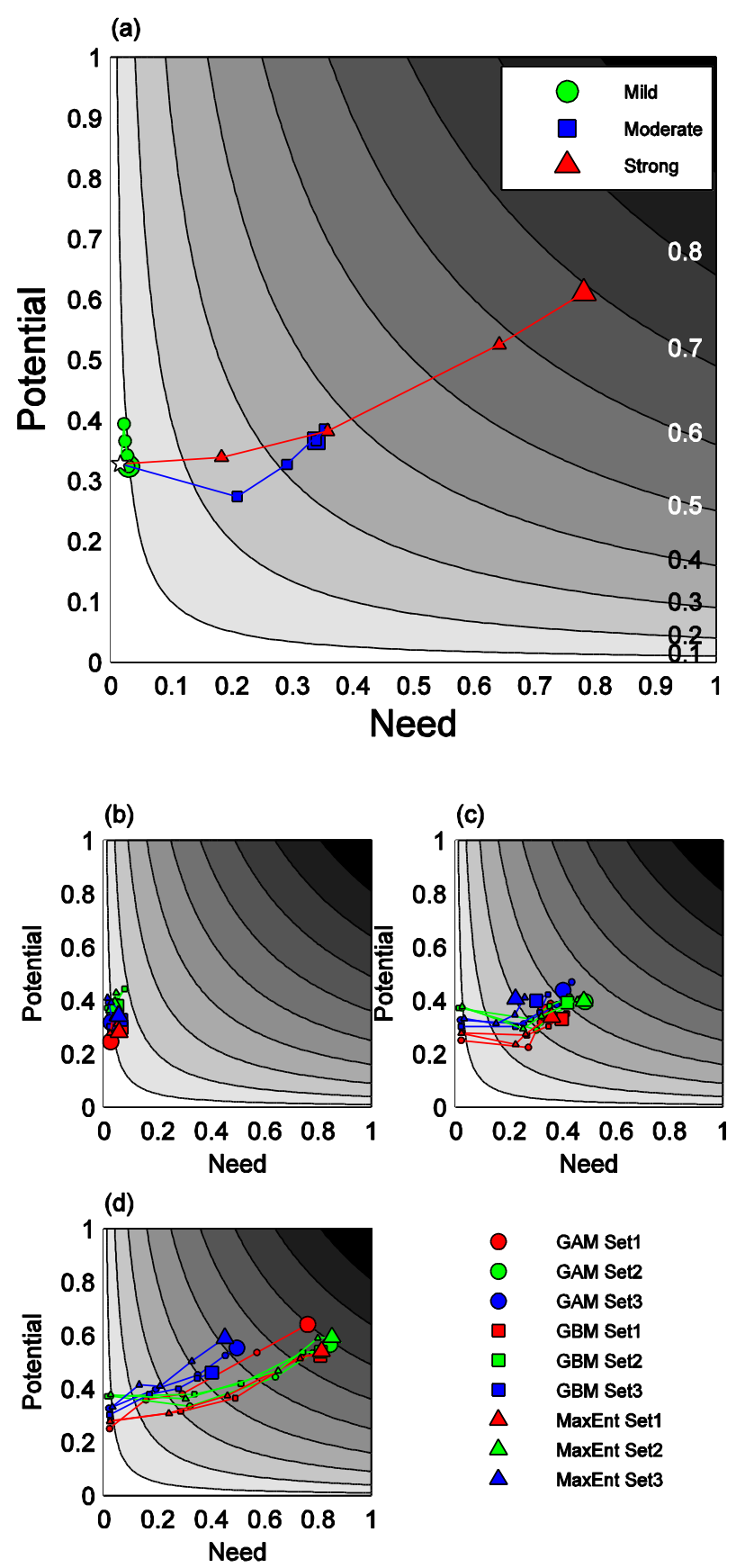

Fig. 2. (a) Consensus model trajectories for the migration need, migration potential and the corresponding AM Index of Carex pulicaris $\left(\mathrm{I}_{\mathrm{AM}, \mathrm{t}}\right.$, isoclines in gray scale) for different modeling scenarios . The smaller figure panels present trajectories for individual models per scenario for $C$. pulicaris: (b) mild, (c) moderate and (d) strong climate change scenario. Points on lines represent five different time periods following the line chronologically: starting from1961-1990, continuing through 2010-2039, 2030-2059, 2050-2079 and ending with 2070-2099 (larger sized point). For corresponding plots of all species see Fig. A3. 


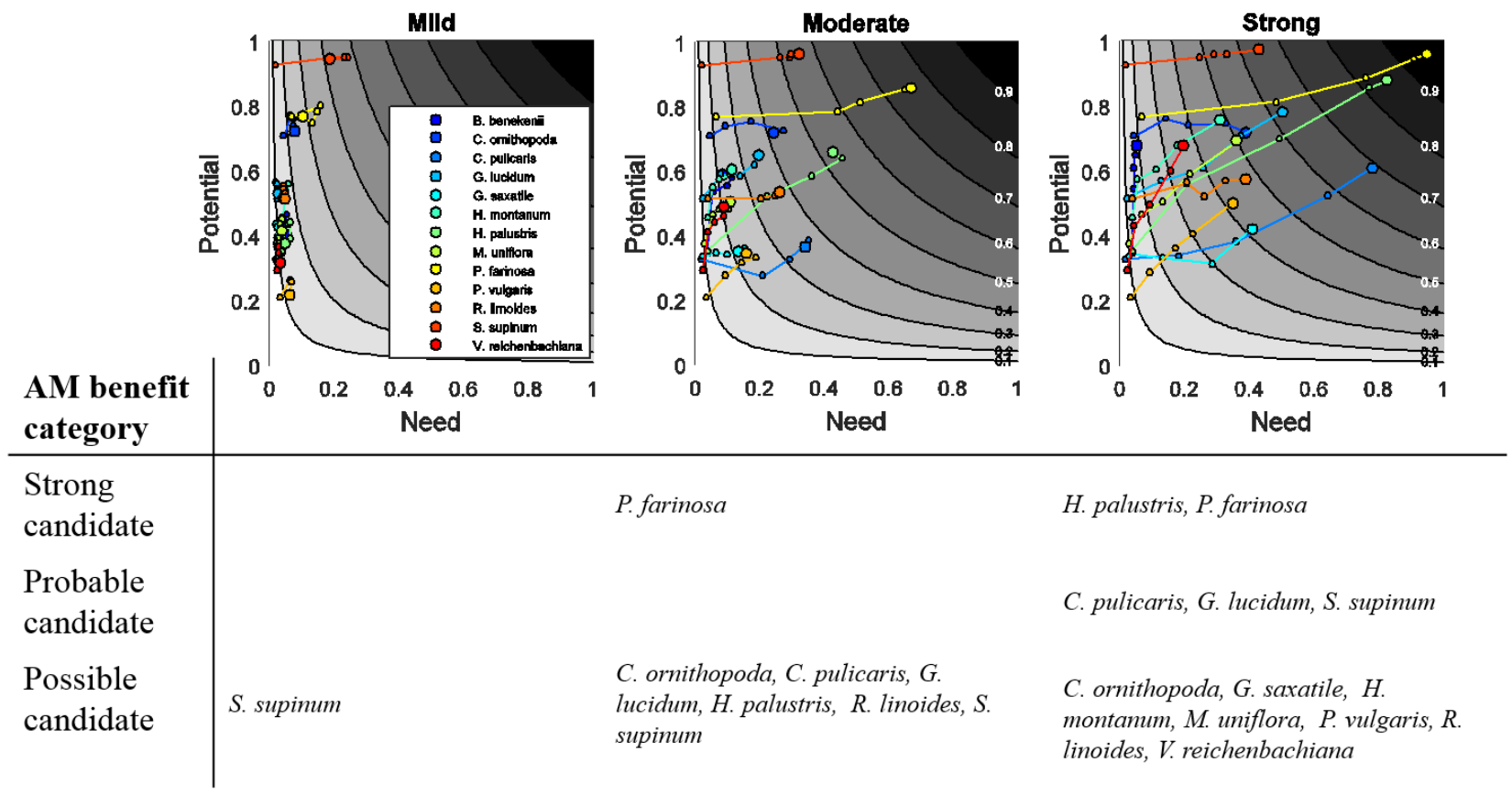

Fig. 3. Trajectories for migration need, migration potential and corresponding AM Index $\left(\mathrm{I}_{\mathrm{AM}, \mathrm{t}}\right.$, isoclines in gray scale) for all species per climate change scenario (a) mild, (b) moderate, (c) strong (dots represent $\mathrm{I}_{\mathrm{AM}, \mathrm{t}}$ values for different time periods: current 1961-1990, and future time periods: 2010-2039, 2030-2059, 2050-2079; larger sized dot = 2070-2099), and table of species per category of benefit from AM in 2070-99. For corresponding table with all time periods, see Table A6. 


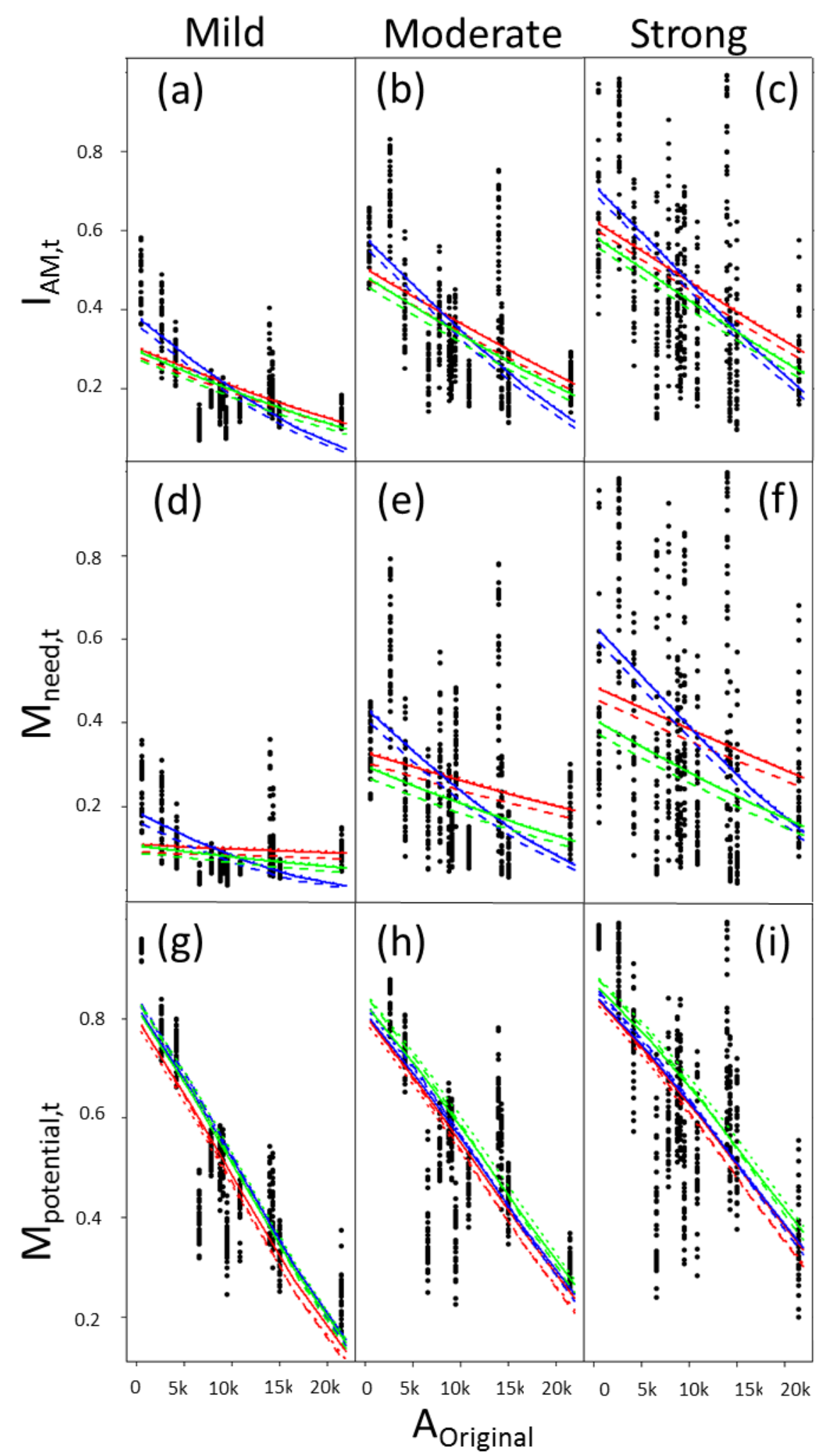

Fig 4. Estimated values for (a-c) $I_{A M, t},(d-f) M_{\text {Need,t }}$, and (g-i) $M_{\text {Potential,t }}$ under (a,d,g) mild, (b,e,h) moderate, and $(\mathrm{c}, \mathrm{f}, \mathrm{i})$ strong climate change plotted against $\mathrm{A}_{\text {Original }}$ (number of cells occupied in original data; e.g., $5 \mathrm{k}=5000$ cells). Line color indicates variables set: blue $=$ set 1 ; red $=$ set 2 ; green $=$ set 3 . Line style indicates modeling method: continuous = GBM; dashed =GAM; dotted = MaxEnt. Data points in black. Estimated values, standard deviations, t-values and p-values for the 
721 linear mixed models used for testing the effect of modeling features on $\mathrm{I}_{\mathrm{AM}, \mathrm{t}}, \mathrm{M}_{\mathrm{Need}, \mathrm{t}}$, and $\mathrm{M}_{\text {Potential,t }}$

722 in Table A7.

723 